\title{
You can't always get what you want: Streamlining stakeholder interests when designing technology-supported services for Active and Assisted Living
}

\author{
Kira Oberschmidt \\ k.oberschmidt@rrd.nl \\ eHealth Group, Roessingh Research \\ and Development \\ Enschede, The Netherlands \\ Biomedical Signals and Systems \\ Group, University of Twente \\ Enschede, The Netherlands
}

\author{
Christiane Grünloh \\ eHealth Group, Roessingh Research \\ and Development \\ Enschede, The Netherlands \\ Biomedical Signals and Systems \\ Group, University of Twente \\ Enschede, The Netherlands
}

\author{
Sefora Tunç \\ Biomedical Signals and Systems \\ Group, University of Twente \\ Enschede, The Netherlands
}

\author{
Lex van Velsen \\ eHealth Group, Roessingh Research \\ and Development \\ Enschede, The Netherlands \\ Biomedical Signals and Systems \\ Group, University of Twente \\ Enschede, The Netherlands
}

\author{
Femke Nijboer \\ Biomedical Signals and Systems \\ Group, University of Twente \\ Enschede, The Netherlands
}

\begin{abstract}
Technological innovations have the potential to support the ageing society, by providing tools to improve quality of life, overall health, preserving independence and reducing loneliness. Acceptance of such innovations and long-term user engagement, however, depends highly on a proper fit between the technology and different kinds of stakeholders (including end-users). In this article, we report on a co-design process with different stakeholders and the negotiation that ensued after the elicitation of their wishes. A first session was held with older adults ( $\mathrm{n}=11$, aged 64 to 88 years), leading to nine challenges and opportunities that older adults face. In a second workshop service and technology providers $(n=8)$ jointly ideated new service concepts. This process laid bare the discrepancies between project objectives, end-user challenges, service providers' interests and researcher aims. This article outlines the difficulties when aligning stakeholder interests and suggests interest mapping and direct, iterative dialogue as a possible solution.
\end{abstract}

\section{CCS CONCEPTS}

- Human-centered computing $\rightarrow$ Participatory design; User studies; $\bullet$ Social and professional topics $\rightarrow$ Seniors.

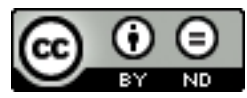

This work is licensed under a Creative Commons Attribution-NoDerivs International 4.0 License.

OzCHI '20, December 2-4, 2020, Sydney, NSW, Australia

ACM ISBN 978-1-4503-8975-4/20/12.

https://doi.org/10.1145/3441000.3441040

\section{KEYWORDS}

Co-design, Older adults, Stakeholder involvement, Stakeholder discrepancies

\section{ACM Reference Format:}

Kira Oberschmidt, Christiane Grünloh, Sefora Tunç, Lex van Velsen, and Femke Nijboer. 2020. You can't always get what you want: Streamlining stakeholder interests when designing technology-supported services for Active and Assisted Living. In 32ND Australian Conference on Human-ComputerInteraction (OzCHI '20), December 2-4, 2020, Sydney, NSW, Australia. ACM, New York, NY, USA, 12 pages. https://doi.org/10.1145/3441000.3441040

\section{INTRODUCTION}

There are a variety of health related changes that occur in the process of ageing. Older adults can encounter problems like reduced mobility [31] or increased loneliness which can lead to decreased quality of life [11,25]. Technological innovations have the potential to support older adults mitigating negative consequences of ageing. For example, technology can improve communication with family and friends for older adults [9], assist older adults in making it possible to live at home longer [42], increase their physical activity $[23,78]$, decrease depressive symptoms [44], or monitor their health remotely [62].

In a review on ageing and technology, Blaschke et al. [9] conclude that research should include the older users in all stages of the development process. Involving the older adults increases the fit of the developed technology with their needs and practices [12] and failing to do so can lead to a technology that is based on erroneous assumptions. For instance, in an interview study by Fleming, Mason and Paxton [33], industry representatives assumed that older adults are less empowered and more passive when it comes to technology. Research is also often based on stereotypical images of older adults [86]. Blindly trusting on stereotypes, without seeking older adults' 
input and/or feedback, could lead to the development of a service that is not useful for actual older adults. Durick and colleagues [30] argue that low use of technology by older adults is not so much related to their age but rather related to the usefulness and benefits of the technology, as perceived by the older adult. Therefore, they reason that existing mainstream products should be made more adaptable for older persons and that older adults need to be included when such technologies are adapted.

One of the main elements of participatory design is the involvement of "partners as a major driver" [10]. Researchers pass some of their control to other partners in order to make the power balance within the project more even [34]. In recent years the call for more involvement of potential end-users, for example older adults, has been growing [54]. At the same time other stakeholders, like service and technology providers or caregivers should not be left out of the development process [85]. Therefore, older adults as well as service and technology providers are involved in this study. Reviews have shown that researchers tend to take on the perspective of one of the participating stakeholders, often those involved in the financing of the project $[21,22]$. Researchers should be conscious of this and try to equally involve the different stakeholders, for example by providing them with suitable information materials [41]. However, ensuring the involvement of different stakeholder groups is not enough. The involved stakeholders might have incongruent interest, as will be described in more detail below. In the worst case this could lead to discrepancies or even conflicts between them. Yet, how to deal with these conflicts has remained largely unexplored to date [17].

This paper outlines a study that is part of a large scale European action research project for active and healthy ageing (Pharaon project) and describes participatory activities involving a variety of stakeholders. The aim is to shed light on views and interests of different parties that are rarely described in research articles but might be inherent in the idea of involving as many key stakeholders as possible. The paper contributes with an overview of congruent and incongruent perspectives, interests or priorities from older adults, service and technology providers, researchers and project management. Furthermore, there are specific points of attention when working with older adults. These will be outlined, together with common problems that older adults are facing regarding their health.

\section{BACKGROUND AND RELATED WORKS}

\subsection{Stakeholder involvement and interests}

eHealth projects can benefit from the involvement of different stakeholders, as they each bring in their own expertise [37, 85]. However, discrepancies among stakeholder perspectives can arise due to their different beliefs, intentions or concerns [5, 6, 48, 82]. Examples of such stakeholder conflicts in eHealth studies can concern topics like efficiency, personalization, willingness to change the current behaviour or enthusiasm about new technology [6]. Additionally, different stakeholder groups have conflicting motivations that can even lead to them following a hidden agenda when participating in a research project [52]. Whenever these conflicts arise in a project, the goal should therefore be to try and find a solution or compromise to these conflicts. How easily stakeholders will cooperate to find such a compromise depends on different factors [48]. According to Johnsen and Normann [48], stakeholders are more likely to cooperate if a small alteration is necessary, rather than a substantial change. Furthermore, trust influences the stakeholders' willingness to compromise. Being open and trusting towards others is more likely to result in cooperation, while mistrust leads to everyone pursuing their own interest, creating more conflict and possibly endangering the project. Johnsen and Normann [48] describe this as the difference between deliberation and power play, warning against the negative impact that power play has for the project. Therefore, finding a trusting, compromising relationship between stakeholders from the start is crucial, especially in large scale projects.

\subsection{Co-design with older adults}

While there is an increased focus on designing products and services for older adults, acceptance is lacking as many products fail to fulfill their needs [60]. Consequently, the importance of including older adults and care professionals in research processes has become increasingly relevant [80]. Therefore, participatory design approaches such as co-design have been introduced [76]. When applied correctly, co-design allows the researcher to uncover the hidden latent knowledge of users (i.e. what they know, feel and dream) [79] by providing them with tools to express themselves [75]. These tools are used in generative sessions, where participants follow the framework of make-enact-tell, i.e. developing a vision, putting it into context and explaining it with words and gesture [13].

Several researchers have conducted co-design sessions with older adults, such as Maaß and Buchmüller [60], who jointly developed an online platform; Davidson and Jensen [27], who prototyped mobile healthcare applications and Lindsay, Jackson, Schofield and Olivier [58], who attempted future-scenario development. What becomes apparent from these cases, is that in some cases older adults must be facilitated differently than e.g. younger participants. Ideas can be to keep sessions short to maintain focus [27], to provide support with envisioning novel technologies [58] and to make the older adults feel valued as experts of their own lives [60]. Techniques that have proven useful are e.g. cultural probes [60], video prompts [58] and scenario-building [58,60]. Other examples of getting closer to the participants' everyday context were applied by Ambe and colleagues [4] and Altay [1], who both promote visiting older participants in their own homes.

\subsection{Concerns for older adults}

Older adults face some challenges that - while not specific to older age - are more relevant to them than to younger users. The European Pharaon project aims to address several of these challenges, three of which will be discussed here in more detail, namely, loneliness, malnutrition and physical activity.

Loneliness has been defined as an aversive experience and reflects a person's subjective experience of deficiencies in their network of social relationships [74]. Weiss [89] distinguished social loneliness (occurring through isolation and caused by lack of social integration), and emotional loneliness (caused by an absence of a reliable attachment figure). In the process of ageing, parts of 
the social network are lost, for example because older adults stop working or because friends and family members pass away [24] The reduced social network can increase the older adults' feelings of loneliness. Reviews have found that loneliness in older adults is associated with lower cognitive function [11] and lower mental and physical health $[59,69]$. Thus, it is important for older adults to stay connected, and technology can offer different ways of connecting with others, for example through social media or video calls [8].

Another problem that increases with older age is that of malnutrition. The European Society for Clinical Nutrition and Metabolism (ESPEN) defines malnutrition as lowered body mass and different body composition due to decreased nutritional intake [19]. Cederholm et al. [19] mention advanced age as one of the factors leading to malnutrition. It comes as no surprise that older adults, especially those that are institutionalized, are often malnourished [49]. While good nutrition has a positive effect on different aspects of quality of life, malnutrition can lead to physical and cognitive decline and can even increase mortality $[2,87]$. Technology could support older adults in monitoring their nutrition, increasing their awareness of malnutrition and helping them improve their diet [7].

In older age, physical activity levels often decline due to the physiological changes that come with ageing, although there is some variability [20]. However, especially for older adults, regular physical activity can have psychological and cognitive benefits and can increase life expectancy. This is why physical activity in older adults is encouraged. Interventions that use technology, like for example accelerometers or pedometers, could help to increase physical activity in older adults by allowing them to self-monitor [23].

\section{METHOD}

In this study, which is part of a European project on healthy and active ageing, different co-design activities were conducted, involving several stakeholders. After a brief description of the project, the sessions that were held with older adults and service and technology providers will be explained.

\subsection{Project description}

The European project encompasses several pilot sites across Europe which address a variety of challenges related to the promotion of a healthy lifestyle in older adults. A key characteristic of the project is the aim to integrate existing technologies, which means that the partners in the consortium contribute to the project with their current technologies that already have a high technology readiness level (TRL). These technologies are then integrated into an overarching system, without deviating too much from the initial concept. The main aim in the Dutch pilot lies in reducing isolation and loneliness and promoting healthy eating and physical activity, through the use of digital tools.

In order to achieve these research aims, co-design sessions and workshops were held with various stakeholders (see Figure 1). First, a workshop was conducted with nine older adults, which was pilot tested beforehand in a session with two older adults. The aim of the workshop with older adults was to gain insights into the daily lives of older adults and to identify challenges they are facing. These challenges were then presented to service and technology providers in different sessions, to see how their services and technologies could support the older adults in dealing with the challenges and to develop and refine innovative concepts.

\subsection{Workshop with older adults}

The goal of the first part of the workshop with older adults was to get a better idea of their daily lives and hear what, if anything, they would like to change or improve. The second part of the workshop focused on how the older adults thought they could bring about these changes. Ethical approval was requested and granted by the Ethical committee of the University of Twente, faculty of Electrical Engineering, Mathematics and Computer Science (Reference number: RP 2020-50).

At the beginning of the workshop, participants were asked to describe their typical day related to four categories (Food, Movement, Social Contacts, Outside Activities). The categories were based on the project aims (i.e., support the ageing society by providing tools to improve quality of life, overall health, preserving independence and reducing loneliness). Participants wrote the elements of their day on differently coloured post-its, indicating the four categories, and attached them to a poster (Figure 2). This exercise is an example of context mapping, as described by Sleeswijk Visser, Stappers, Van der Lugt and Sanders [79] and is similar to the card sorting of daily routine used in a study by Herpich, Rist, Seiderer and André [46]. After discussing the posters with the group, they received another poster and were asked to recreate the first exercise, this time including what they would like to change or do differently in their daily life. In the last exercise the participants were asked to write a short fantasy story describing how they could bridge the gap between the two days that were described. Instructions were left very broad, as to not limit the creativity of the participants. By drawing lots, participants formed four groups, each focussing (mainly) on one of the topics in their stories. The inspiration for this exercise came from a study by Ambe, Brereton, Soro, Buys, and Roe [3] with older creative writers. There was room for participants to read these stories aloud at the end of the workshop.

Before the actual workshop took place, a pilot workshop was conducted with two participants (one female, one male; aged 63 and 72) from a research panel of older adults interested in eHealth services. Based on this pilot, some changes were made to the original plan for the workshop. First, it became clear that participants were immediately able to describe activities in the four categories that related to their daily life, without a separate warming up to this activity. Furthermore, the wording in the second activity was important. Both participants in the pilot found it difficult to improve their daily routine as they had accepted their life as it is. Therefore this exercise was rephrased more neutrally, by asking what aspects of the daily routine could be done differently. Lastly, because there were not many improvements participants saw for their daily life, writing a story about their situation was difficult. It was decided to also allow the participants to write about a peer.

The adapted workshop was then held with users of a 'BoodschappenPlusBus' (=GroceryPlusBus, BPB) in the east of the Netherlands. The bus is an initiative of the Dutch National Foundation for the Elderly (NFE), which offers more than a hundred of these busses throughout the Netherlands. Participants can go on diverse trips, 


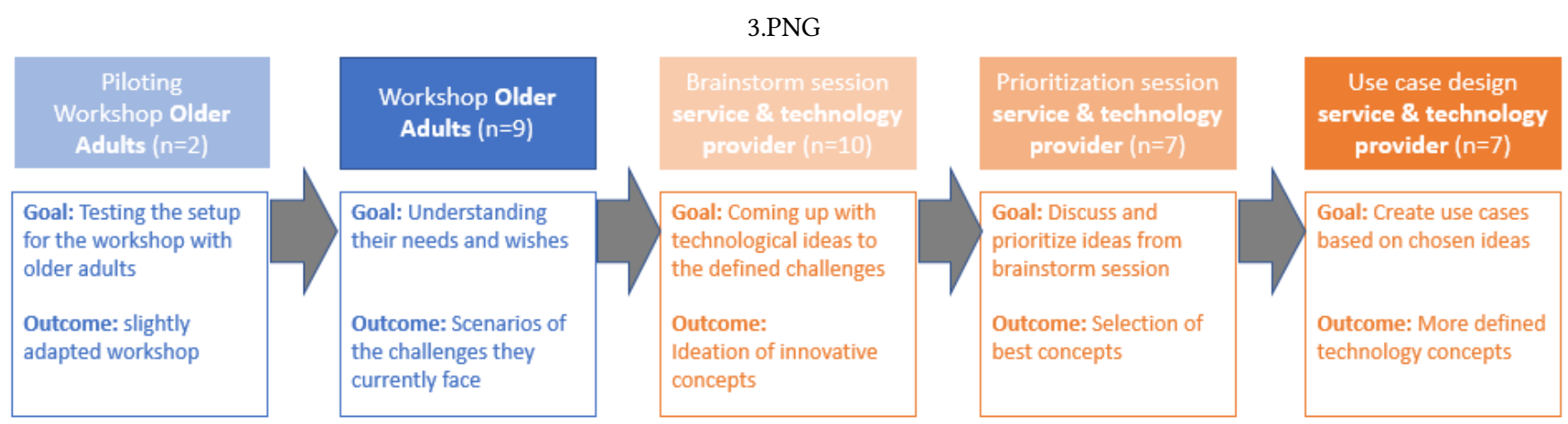

Figure 1: Overview of the sessions in this study, their goal and outcomes.

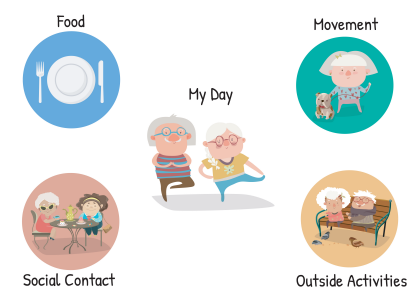

Figure 2: Poster used in the workshop with older adults to describe elements of the their daily routine and possible changes to this routine, divided into the four categories.

for example to a museum or the beach, but also to the supermarket or a mall. The trips are organised by volunteers, who are mostly older adults as well.

For the workshop, seven participants (five female, two male participants; aged between 81 and 88 , mean age 84 ) as well as two BPB volunteers (one male, one female, aged 64 and 73) were recruited. During the workshop, three researchers and two facilitators helped the participants with the exercises, but also stimulated talking, for example, by asking questions about their posters. While the participants were happy to share their answers in an informal way, none of the participants wanted to share the stories they had written in the second part of the workshop with the whole group. After the participants had left, the researchers and facilitators discussed their impressions and the main challenges that they perceived the participants were facing in their daily lives. Additionally, notes and minutes were shared among the researchers. Based on this discussion and the shared notes, challenges were identified and clustered.

\subsection{Sessions with service and technology providers}

Five partners were involved in the initial phase of the project: an ICT company that supports processes in healthcare, a university spin-off company that develops movement sensors, a research institution that works on different projects related to eHealth and rehabilitation technology, a foundation representing older adults, and finally a (technical) university. Originally, a face-to-face workshop with these service and technology providers had been planned. Due to the national Covid-19 measures this workshop was cancelled. Instead, several online meetings were held, and information was shared digitally. Before the first online session all participants received slides and audio commentary about the outcomes of the workshop with the older adults, including the defined challenges.

Adobe Connect ${ }^{1}$ was used to video chat and to split the group into breakout rooms during the workshop. The brainstorming activities in the smaller groups were documented using MURAL ${ }^{2}$, a web-based tool for visual collaboration. The participants were able to add their own ideas, but could also just talk out loud, in which case the facilitator created notes on the MURAL. Information about the content of the workshop, the instructions on how to use the different tools and supplementary material were sent to all participants via email several days before the session. For each of the four partners, between one and three representatives participated in this first session. Additionally, two design students joined in, adding up to a total of ten participants. The workshop was managed by two university researchers and one researcher from the research institution, who each facilitated one group in the brainstorming sessions.

After a short introduction, the online workshop started with brainstorming sessions in a 'speed dating' style. This meant that the participants worked on different challenges and in different groups each round. A rotation schedule was prepared beforehand to make sure that every provider got to give input on each challenge and had the chance to brainstorm with a representative of each other partner at least once. The digital workspace in MURAL (see Figure 3) was prepared before the workshop and included

- Instructions

- Tips for creative brainstorming

- Areas for each breakout room. Each area consisted of space for 2-3 challenges of older adults, each of which was color coded. Each challenge was divided in three group areas, reflecting the different brainstorming rounds.

Due to time constraints and technical problems with Adobe connect (participants lost connections, had to re-enter the room or

\footnotetext{
${ }^{1}$ https://www.adobe.com/products/adobeconnect.html

${ }^{2}$ https://mural.co/
} 


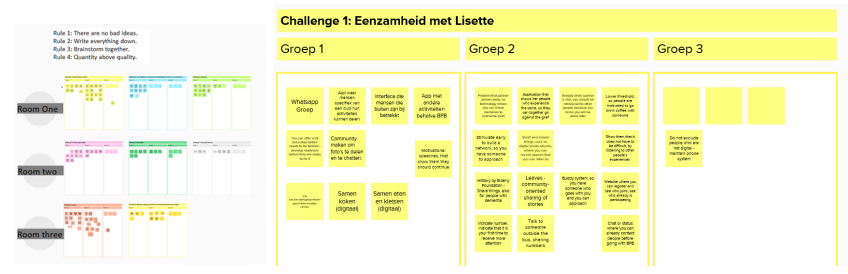

Figure 3: Digital Workspace in MURAL, screenshots during the session with post-it notes attached to challenges

lost audio functionality), only two of the three rounds that had been planned were carried out in this first session. Therefore, the participants were asked to document additional ideas to the MURAL workspace themselves in the days after the workshop. During another meeting a few days later, all technology providers were asked to list the ideas that were the most promising for them.

Based on the selected ideas, use cases were developed by the researchers and presented to the service and technology providers in another online meeting. In the following weeks, several iterations of these use cases were produced, going back and forth between the researchers and the service and technology providers. During mostly bi-weekly online meetings where usually all partners were represented, they discussed their ideas and determined the next steps. Between meetings, these comments were integrated by the researchers, and the partners provided feedback on the new versions of the use cases. As all involved service and technology providers are partners in the project, the meetings with them were less formally structured workshops, but rather sessions to interact and discuss the outcomes.

\subsection{Stakeholder interests}

During the sessions with service and technology providers, as well as in regular project meetings, there was much attention for the different partners' aims and interests. The aims of the researchers, project management, older adults and service and technology providers were summarized by the researchers and compiled in a matrix to show similarities and differences between the parties.

\section{RESULTS AND DISCUSSION}

In the following sections, the results from the stakeholder engagement activities will be described and discussed in relation to the wider literature, starting with the challenges that were mentioned by the older adults. Next, the concepts defined by the service and technology providers are discussed, leading to a reflection on the congruent and incongruent perspectives of the stakeholders and some lessons learned from the process.

\subsection{Challenges and opportunities identified from workshop with older adults}

From the posters, the stories that participants wrote, and from personal discussions with the participants during the workshop, a set of challenges was identified. The researchers clustered these challenges into three categories: Challenges related to older age as a stage of life, personal circumstances and perception by others (see
Figure 4). However, it became apparent that there were also opportunities with regards to healthy and active ageing. In the following, the challenges and opportunities are described and discussed in relation to the wider literature.

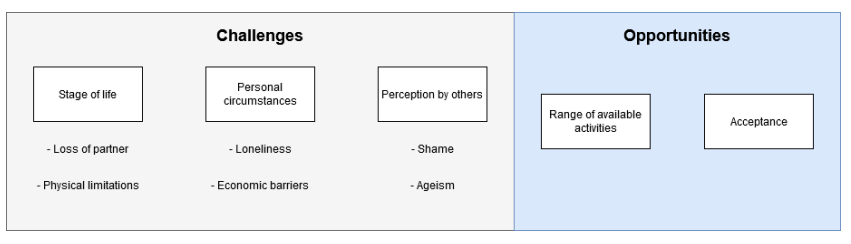

Figure 4: Categories of challenges and opportunities identified from workshop with older adults

4.1.1 Stage of life. Some of the challenges that were identified can be seen as being directly or indirectly related to the process of ageing. Almost all participants had experienced the loss of a spouse, and some also talked about deaths of friends and family members. Second, participants experienced challenges related to their physical abilities, due to the ageing of their body.

Loss of partner. Some participants reported that it is very hard to go out after the death of a partner because usually they would go together but now have to do this fully by themselves. They also reported feeling sad after coming home from a trip, because there was nobody there to tell about their day. This is in line with Spahni, Bennett and Perrig-Chiello [81] who found greater loneliness, more depressive symptoms and lower levels of satisfaction as a consequence of the death of a spouse. Furthermore, there are different responses to grief that require other forms of support, which should be taken into account in the development of interventions [70].

Physical limitations. Another recurring theme was increasing physical limitations. Some participants were no longer able to cycle or to go for long walks. While the older adults reported that they were usually able to adapt to this new situation, one participant got very emotional at the prospect of not being able to join the bus trips anymore if her physical abilities would decrease further. So, while physical decline is something to be accepted and dealt with in older age, these physical restrictions also have an impact on other aspects of the older person's life. Additionally, literature shows that physical decline is related to mental decline [36, 43]. However, technology can provide assistance for dealing with physical decline and the older adults do not have to accept physical restrictions [84].

4.1.2 Personal and contextual circumstances. Another set of challenges can be categorized as being related to more specific personal and contextual circumstances. For example, some older adults might experience more loneliness because they are living by themselves, compared to a care home with frequent social activities. Similarly, economical barriers and therefore lack of money for certain activities is a problem for some of the older adults, but not for others.

Loneliness. Most of the participants lived alone, often still in their old house, though some had moved to apartments for older adults. Their children usually live far away and are busy, so there is less frequent contact with them. Furthermore, family and social circles 
are shrinking, because people move (e.g., to retirement homes) or pass away. As one participant put it, "the group grows smaller and smaller". It should be noted that this loneliness as described by the older adult is an emotional and subjective perception and not the same as more objective concepts like solitude or isolation (as described for example by Durick et al. [30]; Gray and Worlledge [39]). A person who is or lives alone is not necessarily lonely, while somebody who has frequent contact with others can still feel lonely. This challenge should therefore be approached on a more subjective, personal basis.

Economic barriers. Even participants who were aware of the options that the bus offered for going out, were sometimes restricted from going. One of the main barriers that was mentioned was the price of, for example, going to a museum. That older adults may face financial challenges later in life is also reported in the wider literature. The cost for care increases with age, and this can lead to substantial expenses [50]. Together with a small pension or housing costs this can mean that older adults have only little money to spend on activities and leisure time [29].

4.1.3 Perception by others. Three of the challenges that were mentioned fall into the last category: perception by others. First, participants mentioned that older adults can feel ashamed and judged by their peers or others if they engage in unhealthy or socially unaccepted behaviour. Another challenge regarding how others perceive the older adults is ageism.

Shame. Some participants mentioned that they might feel ashamed when being in contact with others who might judge their behaviour. Specific examples they mentioned were unhealthy eating or alcohol consumption, but also lack of good eating manners. Next to alcohol consumption, literature also mentions eating difficulties as reasons for shame in older adults, but recently not much research has been done on this topic [64, 68].

Ageism. Participants emphasized that younger people sometimes underestimate them, and that they do not like being seen as 'old'. They stated that "old people stay fitter in their head [...] and then the years do not count" and that "a 65 year old can sometimes feel older than a 87 year old". These experiences are examples of ageism, or assumptions that are held about a certain age group [16]. Ageism is widely spread for example in our media and in healthcare [77], yet a review by de São José and Amado [28] found no studies on interventions to decrease ageism. Ageism is often related to technology use [56,63]. Usually, young volunteers are recruited to support older adults in using technology, for example in community centers or libraries [56]. It is often overlooked that there are older adults that are able to master technology use by themselves and are able to teach others as well. Maaß and Buchmüller [60] also emphasize that instead of an intergenerational platform, as they had initially envisioned, older adults were more interested in sharing their skills and experiences with peers.

4.1.4 Opportunities. While the focus of the workshops with older adults was to identify challenges in their daily lives, some of the aspects that the participants discussed in relation to healthy and active ageing were identified as opportunities and strengths.The most prominent ones were the many activities that are offered for older adults and their general attitude of accepting changes that come with older age.

Wide range of activities for older adults. While all older adults in the workshop went on trips with the bus, they also all had different other social activities that they joined. These ranged from church dinners and choir repetitions to different sports classes, like Tai chi or swimming. During the workshop some participants requested additional information about activities that they had not heard of and some made notes. This is an opportunity, as activities do not need to be set up from scratch. Rather, there is already a lot out there. The problem is that many people seem to be unaware of these options, or do not know how to approach them. A participant mentioned that it is mostly the same people that go on trips with the bus and asked: "Where are the others?" This notion that it can be difficult to engage people in new projects or to keep them engaged after initial contact has been reported before in other studies [18, 55].

Acceptance. The changing social contacts, losing friends and family and physical decline all demand adjustments from the older adults. Still, the participants were very accepting of these changes that are part of ageing. This is in line with reports that have found older adults to be most content with their lives when compared to younger people [30]. As one participant advised in her story: "Don't throw in the towel. Keep doing things as best as you can". Acceptance is generally positive, for example as a coping strategies to deal with loneliness [51].However, a danger is that older adults become too accepting and miss out on opportunities.

\subsection{Service and technology solutions}

The brainstorm and subsequent discussion with service and technology providers initially resulted in three ideas for services that could help older adults solve their daily challenges by building on existing services and technologies. These three concept services were connecting older adults and volunteers, signaling when older adults might be facing health issues, and giving older adults the opportunity to share their experiences with others. Later the first and third concept were combined so that older adults can both share their experiences and be connected to others.

4.2.1 Connecting and sharing experiences. The first idea that was brought up by the service and technology providers was to connect the older adults, both among themselves and with volunteers like those from the BPB. It was discussed that participants could be matched based on either a common interest or a (care) need, for example needing help with household chores. This idea makes use of the wide range of activities that are offered for older adults, which was seen as an opportunity. Connecting older adults in this way could be effective against the challenge of loneliness as the older adults could meet new people. Furthermore, having a shared interest (e.g., cross-stitching) would provide a topic to start the conversation. Lastly, an older person can be connected with a volunteer who can assist them with chores they are no longer able to do due to physical restrictions. The basis for this service could be provided by the ICT company, in collaboration with the elderly foundation who can reach many older adults and volunteers. 
Connecting older participants with others digitally has been the aim in different projects. For example, "connecting with people" was one of the themes that Fronemann, Pollmann, Weisener and Peissner [35] found in their study on enhancing the wellbeing of older adults. In the Brelomate project [73], older participants have the opportunity to video chat or play one-on-one online games together. However, this project only mentions the online connection between older adults, while one of the aims described by the service and technology providers is to use the online connection to facilitate offline contact.

The service and technology providers decided to integrate another idea in this concept: sharing experiences. This way, older adults would be able to reminisce together online after they had been on a trip with the BPB. As mentioned before the older adults in the workshop liked talking about trips they previously went on and fretted about not having anyone to share stories with after returning home from a trip. Therefore, the idea for a platform to share these experiences with each other was brought up. The use of such a system could help the older adults deal with their loneliness and the loss of a partner. It would also allow others to see the options that are available for older adults, and see how participants experienced activities like BPB trips. Lastly, if the experiences are also shared with others, for example with grandchildren, it could decrease the perception that older adults are inactive and in need of support. A similar idea to this platform for sharing experiences is already included in a technology that the participating research institution developed together with the elderly foundation and which was planned to be integrated. This could be supplemented with the ICT company's database and infrastructure.

Giving older adults the opportunity to share stories with others digitally is not a new idea. In the 'Historytelling' project [88], older adults are encouraged to document their personal history and link remembered moments to a time and place. These stories can be shared with other users and family members. More recently, a similar approach has been taken by Li, Hu, Hengeveld and Hummels [57]. In their study, older adults are prompted to record audio fragments that they can then share with others, for example their grandchildren. While these two studies are focused on telling the older person's life story, the concept that the service and technology providers have come up with does not aim at the big picture in terms of a complete life story. Instead, the idea is to make smaller everyday events more visible and memorable.

4.2.2 Signaling. Another concept that was seen as valuable by some of the service and technology providers was the signaling of potentially unhealthy behaviour, health risks or changes in the older person's life. By monitoring for example their eating and drinking patterns or their physical movement, any changes in their behaviour could be noted. Family members or caregivers can then be notified of these changes and choose to act. The way the service and technology providers saw it, this system would be adaptable to monitor a variety of different variables and could therefore also include concepts related to mental health, like loneliness or grief. For this concept, existing technologies like movement sensors and a nutritional diary could be linked as potential sources of data, and integrated in a combined system.
The technology providers were enthusiastic about the opportunities for expanding this signalling service. Once the general structure is established it would not require much effort to include measures for other (mental) health indicators. Providing a variety of different variables that can be monitored would make the system more adaptable to the needs of each individual user. While for some older adults, diet and movement might be most important, for others loneliness and mental health could be the biggest concerns. Allowing for such personalization would fit in with the advice given by Righi, Sayago and Blat [72] to design an infrastructure in which older users can make adaptations to have the technology accommodate their own situation.

\subsection{Additional interests}

Next to the challenges that the older adults talked about and the concepts that the service and technology providers came up with, there were other factors influencing the outcome of this study. On the one hand there was the project aim to integrate existing services instead of developing completely new ones. Additionally, the influence of the researchers in the project should not be neglected. Both perspectives will be briefly elaborated before the discrepancies between the perspectives are outlined.

4.3.1 Project aim. As mentioned before, this study is part of a larger project which focuses on the integration of existing technologies to help older adults age healthily. So, the goal is explicitly to work with existing technologies instead of developing new services from scratch. The project also emphasizes the participation of end-users and stakeholders as research partners and the need to involve them in co-design sessions. Monitoring overall health status and coaching people to healthier lifestyle is an aim of the project. Despite the fact that the older adults in our workshops did not mention this wish, it is something the project must deliver.

4.3.2 Researcher. The research team in this project also brought their own interests to the table. One of the main aims for the researchers was to include the voice of the older adults and to focus on problems that they brought up. However, after the national Covid-19 measure became active, preventing face-to-face meetings with older adults, the researchers were more engaged with the service and technology providers, with barely any contact to older adults anymore. It was easier to keep in contact with the service and technology providers online, as these remote channels had already been established before. The researchers also brought in some interests with regards to the co-design methods. They were inspired by different creative design methods and tried to incorporate those in the different stakeholder and end-user workshops. Finally, as part of the research team worked for one of the service and technology providers, these interests sometimes overlapped.

\subsection{Congruences and incongruences between the different stakeholder interests}

When aligning the outcomes from the previous sessions it became apparent that there was some dissonance between 1) the challenges that were described by the older adults, 2) the ideas that the technology providers wanted to develop, 3) the researchers ideas and plans for the study, and 4) what was demanded from the overall 
project's perspective. Generally, such incongruences are neither unusual nor necessarily a bad thing, as the involvement of different stakeholders helps develop and implement a fitting technology [85]. However, it is important to identify any potentially conflicting interests early on, especially because they are often not voiced explicitly, but remain rather implicit. The same was true in this project. While the meetings with the different stakeholders were harmonious and no conflicts occurred, some incongruences could be noticed when reflecting on the project. If such differences of interest are not acknowledged and discussed explicitly, they can become bigger problems and even endanger the completion of the project [66].

It should be noted that different interests can also exist or arise within a certain group (e.g. service and technology providers have conflicting ideas, older adults emphasize different topics or researchers disagree over parts of the study). However, mapping these incongruences within parties goes beyond the scope of this paper, therefore only the differences between the four parties in this study (Researchers, older adults, service and technology providers and the project aims and guidelines) are described here. Figure 5 gives an overview of the congruent and incongruent interests of the different stakeholder groups. Overall, these points can be summarized in three different categories: interests regarding methodology, regarding content and ideas about what is feasible.

4.4.1 Methodological interests. Overall, the different parties agreed on stakeholder involvement and participatory methodology as the starting point for this research. However, some differences in interest between the groups became apparent with regards to the methods of the research. The stakeholder participation in the different workshops, especially in the session with older adults, was rather low when it came to the envisioned exercises. While the researchers had expected the use of creative methods to be beneficial to the outcomes of the workshop, the stakeholders seemed less interested in the creative exercises. This relates to what Braten [14] describes as 'Model monopoly', "in which the professional researcher dominates the conversation" [45]. Steen [82] suggests that researchers should deal with this tension by reflecting and becoming aware of their role in the project.

Additionally, not all parties shared the same idea on what the starting point of the research should be. The researchers were interested to first hear from the older adults as envisioned endusers and to use their stories as a basis. On the other hand, the service and technology providers and the project guidelines lay more emphasis on the integration of existing technologies, and were less interested in innovation.

4.4.2 Content. While the partners overall agreed that the service should offer content that supports the older adults, their opinions differed with regard to what this content should be. The first incongruence became apparent between the challenges that were described by the older adults and the concepts that the service and technology providers suggested. None of the suggested concepts tackle the problems that were mentioned regarding economical barriers, shame, and acceptance.

Furthermore, ageism was only touched upon in the concept of "sharing an experience". In contrast, with the signalling concept the service and technology providers suggested a solution that did not directly target any of the challenges that the older adults had described. Additionally, some challenges had already been defined in the project guidelines before the workshop with older adults took place and these challenges only partially match those challenges that were mentioned by the older adults. There was also some disagreement about the 'need for change' of older adults. While the project and the researchers focus on changing some part of the older adults life to improve their health, the older participants generally did not see any need to change something in their lives. This was underlined by the challenge of 'acceptance'.

4.4.3 Feasibility. The last category of incongruences concerns what is feasible within the project. On the one hand this is about the integration of the existing technologies, which service and technology providers and the project agree upon. However, but it is still unclear what this integration will look like. Furthermore, the technologies do not always fit well with the needs and challenges that were voiced by the older adults, and in some cases by other service providers. Therefore, addressing all proposed challenges with the technology at hand is often not feasible. Similarly, Peek et al. [71] describe how it is not possible to address the various needs that older adults have in a single technology.

\subsection{Lessons learned}

A positive aspect that had not been anticipated beforehand was the value of conversations outside of the exercises, both between researchers and participants, and among the older adults themselves. This became apparent right at the start of the workshop, when, as an icebreaker, participants were asked about the best trip they had had with the BPB. They were very enthusiastic when talking about these trips and interacted with each other a lot, for example, by asking questions, adding their memory of the day or just voicing their agreement. Later on in the workshop, the participants seemed to enjoy talking about their lives on a more abstract level, comparing their daily tasks to those of others. This also included discussing topics that they would usually not talk about, like the sadness upon returning to an empty home after a trip with the bus. Even though some of the participants knew each other from trips with the bus they had never really had contact outside of the activities. At the end of the session, three participants exchanged addresses and phone numbers to stay in contact more. This experience shows that it is beneficial to include room for unstructured spontaneous conversations in a workshop, as these can be very informative.

While the older adults enjoyed participating in the workshop, and were overall very willing to share their experiences, they found it difficult to write a fantasy story that bridges the gap between their current typical day and the improved day. This was related to the fact that they saw little room for improvement in their day and therefore did not envision a clear situation to write about. However, writing stories seems to be a difficult exercise for some regardless. For instance, the older adults in the study by Ambe et al. [3] were (amateur) writers, and therefore more familiar with writing (fantasy) stories. Furthermore, Malmborg and colleagues mention that some older adults might generally dislike more 'creative' codesign methods [61]. 


\begin{tabular}{|c|c|c|c|c|}
\hline & Researcher & Older adults & Service and technology providers & Project aims \\
\hline \multirow[t]{2}{*}{ Researchers } & & $\begin{array}{l}\text { + Involvement of } \\
\text { end-users }\end{array}$ & + Involvement of stakeholders & $\begin{array}{l}\text { + Action research / } \\
\text { participatory methodology }\end{array}$ \\
\hline & & $\begin{array}{l}\text { - Need to change } \\
\text { - Use of creative } \\
\text { methods }\end{array}$ & $\begin{array}{l}\text { - Older adults are starting point } \\
\text { (not technology) }\end{array}$ & - Innovation vs. Integration \\
\hline \multirow[t]{2}{*}{ Older adults } & & & + Supporting older adults & + Supporting older adults \\
\hline & & & $\begin{array}{l}\text { - Challenges vs. Concepts } \\
\text { - Contextual problem solving vs. } \\
\text { technology driven approach }\end{array}$ & $\begin{array}{l}\text { - Need to change } \\
\text { - Given challenges }\end{array}$ \\
\hline \multirow{2}{*}{$\begin{array}{l}\text { Service and } \\
\text { technology } \\
\text { providers }\end{array}$} & & & & + Use existing technology \\
\hline & & & & $\begin{array}{l}\text { - Feasibility to integrate on } \\
\text { large scale }\end{array}$ \\
\hline Project aims & & & & \\
\hline
\end{tabular}

Figure 5: Overview of congruent (green) and incongruent (red) interest between the four parties.

Older adults specifically seem to be a group that is often misunderstood or judged wrongly by various other stakeholders. Literature points out different opinions or values between older adults and relatives, care professionals, local governments, businesses and service providers [32, 47, 53, 83]. However, Teles et al. [83] argue that these conflicts can be overcome by collaborating with multiple stakeholders. Initially, the plan was to have a meeting including both service and technology providers and older adults to decide on the concepts together. However, the national Covid-19 measures made this impossible. Aligning the aims of the different stakeholders face-to-face and being able to directly respond to each other and ask questions might have led to other outcomes. This was also recommended by Greenhalgh et al. [40], in that "more effective inter-stakeholder dialogue must occur to establish an organising vision that better accommodates competing discourses". As Greenhalgh et al. point out, however, consensus might be neither realistic nor a desirable goal, but such a dialogue can lead to accommodation in which other perspectives and practices are acknowledged and adapted towards [40].

This project has shown that the process of aligning stakeholder interests takes time and several iterations. Coming together in different groups (e.g. first within a stakeholder group, later combined), and using different methods for alignment (like the matrix suggested above, repertory grids [15] or stakeholder tokens [90]) can make needs more tangible, both for the stakeholders themselves, and between groups. This can be enhanced by including the relations that form between individual stakeholders or stakeholder groups [26]. In the current situation it will be challenging to adapt these methods to make them work in an online setting. However, a positive side effect of the current pandemic is that most people, and especially older adults, have become more proficient using online tools [65]. Additionally, there are ways of letting older adults share their ideas in online research that were proven before, for example through blogs [38] or discussion boards [67]. Therefore, our suggestion for future projects is to take some time to align stakeholder interests and to return to this point throughout the project. For example, our team has incorporated regular check-ins asking about each partners aim for the overall project, their goals for the coming period or even their wishes for the current meeting.

While stakeholder involvement is increasing, and different stakeholder groups like user, care professionals or technology developers are being included, researchers tend to see themselves as separate from these groups. However, as Steen [82] describes, researchers have an important position in the project, which is sometimes in disagreement with that of users or other stakeholders. He suggests that researchers should therefore examine their own role and reflect on the decisions they made. By including our research team as one of the stakeholders in our analysis we tried to be reflective of our actions. This is an important first step to enable mapping out stakeholder interests and identify potential conflicts as was done in this paper. However, the stakeholder interests were identified and described by the authors of this paper and not articulated by each stakeholder during the mapping activity. The process of aligning stakeholder interests would benefit from following a participatory approach in which stakeholders can represent their own interests and identify potential conflicts with interests of others. This could strengthen the role of other stakeholders and help equalize the power balance in the project [34].

From the onset of the project the aim was to develop a technological solution that does not reinforce ageist stereotypes, which 
is why a co-design approach was chosen. Despite this overarching aim and being critically aware of our own implicit biases, the nature of the project (integration of existing technologies) and methodological decisions might still have some ageist assumptions embedded of which we were not aware at the time. For instance, by applying a problem-solving approach in the workshop with older adults, this activity focused on challenges not on strengths. It became apparent that ageism is not eradicated through self-awareness alone and sometimes the critical eye of an external party is needed. Researchers working with older adults should let their work be checked periodically.

\section{LIMITATIONS}

One limitation of this study is participant bias. The older adults in both the workshop and the pilot were very active and outgoing. However, especially in the pilot study, the participants talked about others in their community or surroundings that are less active. Furthermore, the National Foundation for the Elderly that was involved represents a much broader group of older adults. Therefore, the challenges that were mentioned apply not only to active older adults, but also to those who are less involved in a community. Nonetheless the aim for future studies should be to also include other older adults, who might be harder to reach.

Due to the national Covid-19 measures, meetings between the older adults and the service and technology providers were not possible. Such a meeting had originally been planned to stimulate conversations between the stakeholders. As was stated above, such direct discourse between the stakeholders could have helped mitigate the discrepancies between the challenges put forward and the solutions ideated and might even have led to a consensus between them. The service and technology providers were included in online discussions on this topic, but it was expected that it would be too difficult to involve older adults in these online sessions. However, the online meetings included representatives of the National Foundation for the Elderly. Nevertheless, direct contact between older adults and service and technology providers would have been preferable.

\section{CONCLUSION}

This study describes the start of a large scale project that involves older adults and service and technology providers, as well as the researchers and overarching project aims. In this paper the different interests of these various parties are made explicit. Generally, opinions differed when it comes to methodological or content-related topics, or issues of feasibility. While such incongruences often remain implicit, mapping and discussing the different positions can enhance the cooperation between parties. Projects should pay attention to the interests of involved parties and foster open communication between them to prevent conflicts later on in the process. Furthermore, researchers should not shy away from reflection on their own role in the project and critically examine themselves as one of the stakeholders. Lastly, accidental ageism can happen even to those researchers who actively try prevent this. They should be reflective and engage in discussion with others to see where they might be overlooking their own ageist assumptions.

\section{ACKNOWLEDGMENTS}

We thank all study participants, the National Foundation for the Elderly in the Netherlands (Nationaal Ouderenfonds), the service and technology providers and the facilitators who participated in the first workshop. Special thanks to the anonymous reviewers for their valuable and constructive feedback and for raising awareness of some implicit assumptions in the first version of this paper. This project has received funding from the European Union's Horizon 2020 research and innovation programme under grant agreement No 857188 .

\section{REFERENCES}

[1] Burçak Altay. 2017. Developing empathy towards older adults in design. Educational Gerontology 43, 4 (2017), 198-208.

[2] Eleni Amarantos, Andrea Martinez, and Johanna Dwyer. 2001. Nutrition and quality of life in older adults. The fournals of Gerontology series A: Biological sciences and Medical sciences 56, suppl_2 (2001), 54-64.

[3] Aloha Hufana Ambe, Margot Brereton, Alessandro Soro, Laurie Buys, and Paul Roe. 2019. The adventures of older authors: Exploring futures through co-design fictions. In Proceedings of the 2019 CHI Conference on Human Factors in Computing Systems. 1-16.

[4] Aloha Hufana Ambe, Margot Brereton, Alessandro Soro, Min Zhen Chai, Laurie Buys, and Paul Roe. 2019. Older people inventing their personal internet of things with the IoT un-kit experience. In Proceedings of the 2019 CHI Conference on Human Factors in Computing Systems. 1-15.

[5] Tariq Osman Andersen, Jørgen Peter Bansler, Finn Kensing, Jonas Moll, Troels Mønsted, Karen Dam Nielsen, Olav Wendelboe Nielsen, Helen Høgh Petersen, and Jesper Hastrup Svendsen. 2019. Aligning concerns in telecare: Three concepts to guide the design of patient-centred e-health. Computer Supported Cooperative Work (CSCW) 28, 6 (2019), 1039-1072.

[6] Kirsti Askedal and Leif Skiftenes Flak. 2017. Stakeholder Contradictions in Early Stages of eHealth Efforts. In Proceedings of the 50th Hawaii International Conference on System Sciences.

[7] Caroline Farsjø Aure, Anders Kluge, and Anne Moen. 2020. Promoting dietary awareness: Home-dwelling older adults' perspectives on using a nutrition application. International fournal of Older People Nursing (2020), e12332.

[8] Ron Baecker, Kate Sellen, Sarah Crosskey, Veronique Boscart, and Barbara Barbosa Neves. 2014. Technology to reduce social isolation and loneliness. ASSETS14 - Proceedings of the 16th International ACM SIGACCESS Conference on Computers and Accessibility (2014), 27-34. https://doi.org/10.1145/2661334.2661375

[9] Christina M Blaschke, Paul P Freddolino, and Erin E Mullen. 2009. Ageing and technology: A review of the research literature. British fournal of Social Work 39, 4 (2009), 641-656.

[10] Susanne Bødker and Morten Kyng. 2018. Participatory design that matters-Facing the big issues. ACM Transactions on Computer-Human Interaction (TOCHI) 25, 1 (2018), 1-31.

[11] Lisa Boss, Duck-Hee Kang, and Sandy Branson. 2015. Loneliness and cognitive function in the older adult: a systematic review. International Psychogeriatrics 27, 4 (2015), 541-553.

[12] Andrea Botero and Sampsa Hyysalo. 2013. Ageing together: Steps towards evolutionary co-design in everyday practices. CoDesign 9, 1 (2013), 37-54.

[13] Eva Brandt, Thomas Binder, and Elizabeth B-N Sanders. 2012. Tools and techniques: ways to engage telling, making and enacting. In Routledge international handbook of participatory design. Routledge, 165-201.

[14] Stein Braten. 1973. Model monopoly and communication: Systems theoretical notes on democratization. Acta Sociologica 16, 2 (1973), 98-107.

[15] Jim Buchan, Muneera Bano, Didar Zowghi, Stephen MacDonell, and Amrita Shinde. 2017. Alignment of stakeholder expectations about user involvement in agile software development. In Proceedings of the 21st International Conference on Evaluation and Assessment in Software Engineering. 334-343.

[16] Robert N Butler. 1969. Age-ism: Another form of bigotry. The gerontologist 9 , 4_Part_1 (1969), 243-246.

[17] Âsa Cajander and Christiane Grünloh. 2019. Electronic health records are more than a work tool: conflicting needs of direct and indirect stakeholders. In Proceedings of the 2019 CHI Conference on Human Factors in Computing Systems. $1-13$.

[18] Kayla Carucci and Kentaro Toyama. 2019. Making well-being: Exploring the role of makerspaces in long-term care facilities. Conference on Human Factors in Computing Systems - Proceedings (2019), 1-12. https://doi.org/10.1145/3290605. 3300699

[19] Tommy Cederholm, ROCCO Barazzoni, Peter Austin, Peter Ballmer, GIANNI Biolo, Stephan C Bischoff, C Compher, Isabel Correia, T Higashiguchi, and M Holst. 2017. ESPEN guidelines on definitions and terminology of clinical nutrition. 
Clinical nutrition 36, 1 (2017), 49-64.

[20] Wojtek J Chodzko-Zajko, David N Proctor, Maria A Fiatarone Singh, Christopher T Minson, Claudio R Nigg, George J Salem, and James S Skinner. 2009. Exercise and physical activity for older adults. Medicine \& science in sports \& exercise 41, 7 (2009), 1510-1530.

[21] Roger Clarke. 2016. An Empirical Assessment of Researcher Perspectives.. In Bled eConference. 42.

[22] Roger Clarke and Robert M Davison. 2020. Researcher Perspective in the IS Discipline: An Empirical Study of Articles in the Basket of 8 Journals. (2020).

[23] Carly Cooper, Anne Gross, Chad Brinkman, Ryan Pope, Kelli Allen, Susan Hastings, Bard E Bogen, and Adam P Goode. 2018. The impact of wearable motion sensing technology on physical activity in older adults. Experimental gerontology 112 (2018), 9-19.

[24] Erin York Cornwell and Linda J Waite. 2009. Social disconnectedness, perceived isolation, and health among older adults. Fournal of health and social behavior 50, 1 (2009), 31-48.

[25] James Alexander Crewdson. 2016. The effect of loneliness in the elderly population: A review. Healthy Aging \& Clinical Care in the Elderly 8 (2016), 1

[26] Christopher A Le Dantec and Carl DiSalvo. 2013. Infrastructuring and the formation of publics in participatory design. Social Studies of Science 43, 2 (2013), 241-264.

[27] Jennifer L Davidson and Carlos Jensen. 2013. Participatory design with older adults: an analysis of creativity in the design of mobile healthcare applications. In Proceedings of the 9th ACM Conference on Creativity \& Cognition. 114-123.

[28] José Manuel Sousa de São José and Carla Alexandra Filipe Amado. 2017. On studying ageism in long-term care: a systematic review of the literature. International Psychogeriatrics 29, 3 (2017), 373-387.

[29] Neda Delfani, Johan De Deken, and Caroline Dewilde. 2015. Poor because of low pensions or expensive housing? The combined impact of pension and housing systems on poverty among the elderly. International fournal of Housing Policy 15, 3 (2015), 260-284.

[30] Jeannette Durick, Toni Robertson, Margot Brereton, Frank Vetere, and Bjorn Nansen. 2013. Dispelling ageing myths in technology design. In Proceedings of the 25th Australian Computer-Human Interaction Conference: Augmentation, Application, Innovation, Collaboration. 467-476.

[31] P R Ebeling, F Cicuttini, D Scott, and G Jones. 2019. Promoting mobility and healthy aging in men: a narrative review. Osteoporosis International (2019), 1-12.

[32] Jane Farmer, Lorna Philip, Gerry King, John Farrington, and Marsaili MacLeod. 2010. Territorial tensions: misaligned management and community perspectives on health services for older people in remote rural areas. Health \& Place 16, 2 (2010), 275-283.

[33] Aysha Fleming, Claire Mason, and Gillian Paxton. 2018. Discourses of technology, ageing and participation. Palgrave Communications 4, 1 (2018), 1-9.

[34] Wendy Frisby, Colleen J Reid, Sydney Millar, and Larena Hoeber. 2005. Putting "participatory" into participatory forms of action research. Fournal of sport management 19, 4 (2005), 367-386.

[35] Nora Fronemann, Kathrin Pollmann, Alicia Weisener, and Matthias Peissner. 2016 Happily ever after: Positive aging through positive design. ACM International Conference Proceeding Series 23-27-Octo (2016). https://doi.org/10.1145/2971485. 2996740

[36] Guilherme Eustaquio Furtado, Adriana Caldo, Tais Rieping, Edith Filaire, Eef Hogervorst, Ana Maria Botelho Teixeira, and Jose Pedro Ferreira. 2018. Physical frailty and cognitive status over-60 age populations: A systematic review with meta-analysis. Archives of gerontology and geriatrics 78 (2018), 240-248.

[37] Jai Ganesh. 2004. E-health drivers, applications, challenges ahead and Strategies: a conceptual framework. Indian fournal of Medical Informatics 1, 1 (2004), 40-48.

[38] M Rebecca Genoe, Toni Liechty, Hannah R Marston, and Victoria Sutherland. 2016. Blogging into retirement: Using qualitative online research methods to understand leisure among baby boomers. Fournal of Leisure Research 48, 1 (2016), $15-34$.

[39] Anne Gray and George Worlledge. 2018. Addressing loneliness and isolation in retirement housing. Ageing \& Society 38, 3 (2018), 615-644

[40] Trisha Greenhalgh, Rob Procter, Joe Wherton, Paul Sugarhood, and Sara Shaw. 2012. The organising vision for telehealth and telecare: discourse analysis. BMF open 2, 4 (2012).

[41] Erik Grönvall and Morten Kyng. 2013. On participatory design of home-based healthcare. Cognition, technology \& work 15, 4 (2013), 389-401.

[42] Giuliano Grossi, Raffaella Lanzarotti, Paolo Napoletano, Nicoletta Noceti, and Francesca Odone. 2019. Positive technology for elderly well-being: A review. Pattern Recognition Letters (2019)

[43] Chao Guo, Ping He, Xinming Song, Gong Chen, and Xiaoying Zheng. 2018. Comorbid mental disability among Chinese elderly with motor disability: Based on a nationwide survey. PloS one 13, 4 (2018).

[44] Boniface Harerimana, Cheryl Forchuk, and Tony O'Regan. 2019. The use of technology for mental healthcare delivery among older adults with depressive symptoms: a systematic literature review. International journal of mental health nursing 28, 3 (2019), 657-670.
[45] Gillian R Hayes. 2011. The relationship of action research to human-computer interaction. ACM Transactions on Computer-Human Interaction (TOCHI) 18, 3 (2011), 1-20.

[46] Madita Herpich, Thomas Rist, Andreas Seiderer, and Elisabeth André. 2017. Towards a Gamified Recommender System for the Elderly. In Proceedings of the 2017 International Conference on Digital Health. 211-215.

[47] Jina Huh, Thai Le, Blaine Reeder, Hilaire J Thompson, and George Demiris. 2013. Perspectives on wellness self-monitoring tools for older adults. International journal of medical informatics 82, 11 (2013), 1092-1103.

[48] Hans Chr Garmann Johnsen and Roger Normann. 2004. When research and practice collide: The role of action research when there is a conflict of interest with stakeholders. Systemic Practice and Action Research 17, 3 (2004), 207-235.

[49] Matthias J Kaiser, Jürgen M Bauer, Christiane Rämsch, Wolfgang Uter, Yves Guigoz, Tommy Cederholm, David R Thomas, Patricia S Anthony, Karen E Charlton, and Marcello Maggio. 2010. Frequency of malnutrition in older adults: a multinational perspective using the mini nutritional assessment. fournal of the American Geriatrics Society 58, 9 (2010), 1734-1738.

[50] Norah C Keating, Janet E Fast, Donna S Lero, Sarah J Lucas, and Jacquie Eales. 2014. A taxonomy of the economic costs of family care to adults. The fournal of the Economics of Ageing 3 (2014), 11-20.

[51] Kalpa Kharicha, Jill Manthorpe, Steve Iliffe, Nathan Davies, and Kate Walters. 2018. Strategies employed by older people to manage loneliness: systematic review of qualitative studies and model development. International psychogeriatrics 30, 12 (2018), 1767-1781.

[52] Philipp N Klöcker, Rainer Bernnat, and Daniel J Veit. 2015. Stakeholder behavior in national eHealth implementation programs. Health Policy and Technology 4, 2 (2015), 113-120.

[53] Ella Kolkowska, Anneli Avatare Nöu, Marie Sjölinder, and Isabella Scandurra. 2017. To capture the diverse needs of welfare technology stakeholders-evaluation of a value matrix. In International Conference on Human Aspects of IT for the Aged Population. Springer, 404-419.

[54] André Kushniruk and Christian Nøhr. 2016. Participatory design, user involvement and health IT evaluation. Stud Health Technol Inform 222 (2016), 139-151.

[55] Lina Lee. 2019. Creativity and Emotional Attachment as a Guide to Factors of Engagement for Elderly Interaction with Technology. In Proceedings of the 2019 on Creativity and Cognition. 664-669.

[56] Noah Lenstra. 2017. Agency and ageism in the community-based technology support services used by older adults. First Monday 22, 8 (2017).

[57] Cun Li, Jun Hu, Bart Hengeveld, and Caroline Hummels. 2018. Slots-story: facilitate inter-generational life story sharing and preservation of the elderly. In Proceedings of the 10th Nordic Conference on Human-Computer Interaction. 691-695.

[58] Stephen Lindsay, Daniel Jackson, Guy Schofield, and Patrick Olivier. 2012. Engaging older people using participatory design. In Proceedings of the SIGCHI conference on human factors in computing systems. 1199-1208.

[59] Conor Ó Luanaigh and Brian A Lawlor. 2008. Loneliness and the health of older people. International fournal of Geriatric Psychiatry: A journal of the psychiatry of late life and allied sciences 23, 12 (2008), 1213-1221.

[60] Susanne Maaß and Sandra Buchmüller. 2018. The crucial role of cultural probes in participatory design for and with older adults. $i$-com 17, 2 (2018), 119-135.

[61] Lone Malmborg, Erik Grönvall, Jörn Messeter, Thomas Raben, and Katharina Werner. 2016. Mobilizing Senior Citizens in Co-Design of Mobile Technology. International fournal of Mobile Human Computer Interaction (IFMHCI) 8, 4 (2016), $42-67$.

[62] Shwetambara Malwade, Shabbir Syed Abdul, Mohy Uddin, Aldilas Achmad Nursetyo, Luis Fernandez-Luque, Xinxin Katie Zhu, Liezel Cilliers, Chun-Por Wong, Panagiotis Bamidis, and Yu-Chuan Jack Li. 2018. Mobile and wearable technologies in healthcare for the ageing population. Computer methods and programs in biomedicine 161 (2018), 233-237.

[63] I. Mannheim, E. Schwartz, W. Xi, S.C. Buttigieg, M. McDonnell-Naughton, E.J.M. Wouters, and Y. van Zaalen. 2019. Inclusion of older adults in the research and design of digital technology. International Journal of Environmental Research and Public Health 16, 19 (2019). https://doi.org/10.3390/ijerph16193718

[64] John A Menninger. 2002. Assessment and treatment of alcoholism and substancerelated disorders in the elderly. Bulletin of the Menninger Clinic 66, 2 (2002), 166-183.

[65] Nancy Morrow-Howell, Natalie Galucia, and Emma Swinford. 2020. Recovering from the COVID-19 pandemic: A focus on older adults. Fournal of aging \& social policy (2020), 1-9.

[66] Krishnan Mysore, Konstantinos Kirytopoulos, Seungjun Ahn, and Tony Ma. 2019. Adversarial factors in multi-stakeholders' engagement of global-IT projects. International fournal of Managing Projects in Business (2019).

[67] Eun-Shim Nahm, Barbara Resnick, Mary DeGrezia, and Rebecca Brotemarkle. 2009. Use of discussion boards in a theory-based health web site for older adults. Nursing Research 58, 6 (2009), 419-426.

[68] Maria Nyberg, Viktoria Olsson, Zada Pajalic, Gerd Örtman, Håkan S Andersson, Anna Blücher, Karin Wendin, and Albert Westergren. 2015. Eating difficulties, 
nutrition, meal preferences and experiences among elderly: a literature overview from a Scandinavian context. fournal of Food Research 4, 1 (2015), 22-37.

[69] Anthony D Ong, Bert N Uchino, and Elaine Wethington. 2016. Loneliness and health in older adults: A mini-review and synthesis. Gerontology 62, 4 (2016), 443-449.

[70] Carol H Ott, Robert J Lueger, Sheryl T Kelber, and Holly G Prigerson. 2007. Spousal bereavement in older adults: Common, resilient, and chronic grief with defining characteristics. The fournal of nervous and mental disease 195, 4 (2007), 332-341.

[71] Sebastiaan Theodorus Michaël Peek, Eveline J M Wouters, Katrien G Luijkx, and Hubertus J M Vrijhoef. 2016. What it takes to successfully implement technology for aging in place: focus groups with stakeholders. Fournal of medical Internet research 18, 5 (2016), e98.

[72] Valeria Righi, Sergio Sayago, and Josep Blat. 2017. When we talk about older people in $\mathrm{HCI}$, who are we talking about? Towards a 'turn to community'in the design of technologies for a growing ageing population. International fournal of Human-Computer Studies 108, January 2016 (2017), 15-31. https://doi.org/10. 1016/j.ijhcs.2017.06.005

[73] Gernot Rottermanner, Peter Judmaier, Shadja El Aeraky, Christian Gradl, and Sabine Sommer. 2018. Brelomate: a multiscreen communication and gaming platform to enhance social inclusion. In Proceedings of the 10th Nordic Conference on Human-Computer Interaction. 928-931.

[74] Dan Russell, Carolyn E Cutrona, Jayne Rose, and Karen Yurko. 1984. Social and emotional loneliness: an examination of Weiss's typology of loneliness. Journal of personality and social psychology 46, 6 (1984), 1313.

[75] Elizabeth B-N Sanders and Pieter Jan Stappers. 2008. Co-creation and the new landscapes of design. Co-design 4, 1 (2008), 5-18.

[76] Liz Sanders. 2012. Convivial Toolbox: Generative Research for the Front End of Design pdf by. (2012)

[77] Kerry Sargent-Cox. 2017. Ageism: we are our own worst enemy. International psychogeriatrics 29, 1 (2017), 1-8.

[78] Nina Skjæret, Ather Nawaz, Tobias Morat, Daniel Schoene, Jorunn Lægdheim Helbostad, and Beatrix Vereijken. 2016. Exercise and rehabilitation delivered through exergames in older adults: An integrative review of technologies, safety and efficacy. International journal of medical informatics 85, 1 (2016), 1-16.

[79] Froukje Sleeswijk Visser, Pieter Jan Stappers, Remko Van der Lugt, Elizabeth B-N N Sanders, Froukje Sleeswijk Visser, Pieter Jan Stappers, Remko Van der Lugt, and Elizabeth B-N N Sanders. 2005. Contextmapping: experiences from practice. CoDesign 1, 2 (2005), 119-149. https://doi.org/10.1080/15710880500135987

[80] Carolien H M Smits, Hugo K Van den Beld, Marja J Aartsen, and Johannes J F Schroots. 2014. Aging in the Netherlands: state of the art and science. The Gerontologist 54, 3 (2014), 335-343.

[81] Stefanie Spahni, Kate M Bennett, and Pasqualina Perrig-Chiello. 2016. Psychological adaptation to spousal bereavement in old age: The role of trait resilience, marital history, and context of death. Death studies 40, 3 (2016), 182-190.

[82] Marc Steen. 2011. Tensions in human-centred design. CoDesign 7, 1 (2011), 45-60.

[83] Soraia Teles, Diotima Bertel, Andrea Ch Kofler, Stefan H Ruscher, and Constança Paúl. 2017. A Multi-perspective View on AAL Stakeholders' Needs-A User-centred Requirement Analysis for the Activeadvice European Project. In International Conference on Information and Communication Technologies for Ageing Well and e-Health, Vol. 2. SCITEPRESS, 104-116.

[84] Marija Tomšič, Barbara Domajnko, and Melita Zajc. 2018. The use of assistive technologies after stroke is debunking the myths about the elderly. Topics in stroke rehabilitation 25,1 (2018), 28-36.

[85] Julia E W C van Gemert-Pijnen, Nicol Nijland, Maarten van Limburg, Hans C Ossebaard, Saskia M Kelders, Gunther Eysenbach, and Erwin R Seydel. 2011. A holistic framework to improve the uptake and impact of eHealth technologies. fournal of medical Internet research 13, 4 (2011), e111.

[86] John Vines, Gary Pritchard, Peter Wright, Patrick Olivier, and Katie Brittain. 2015. An age-old problem: Examining the discourses of ageing in HCI and strategies for future research. ACM Transactions on Computer-Human Interaction (TOCHI) 22, 1 (2015), 1-27.

[87] Dorothee Volkert. 2013. Malnutrition in older adults-urgent need for action: plea for improving the nutritional situation of older adults. Gerontology 59, 4 (2013), 328-333.

[88] Torben Volkmann, Michael Sengpiel, and Nicole Jochems. 2016. Historytelling: A website for the elderly a human-centered design approach. ACM International Conference Proceeding Series 23-27-Octo (2016). https://doi.org/10.1145/2971485. 2996735

[89] Robert S Weiss. 1973. Loneliness: The experience of emotional and social isolation. (1973).

[90] Daisy Yoo. 2018. Stakeholder Tokens: a constructive method for value sensitive design stakeholder analysis. Ethics and Information Technology (2018), 1-5. 